\title{
Problems in Library Construction of Newly-upgraded Local
}

\section{Undergraduate Institutions}

\author{
Chunlan Qiu \\ E-mail:jxust@126.com \\ Library, Jiangxi University of Science and Technology, Ganzhou 341000, China \\ Rongsheng Wen \\ Library, Jiangxi University of Science and Technology, Ganzhou 341000, China
}

\begin{abstract}
Based on an analysis on the features and problems in the libraries of some newly-upgraded local undergraduate institutions, this article finally comes to a series of management countermeasures.

Keywords: Upgraded, Local undergraduate institutions, Library, Construction

\section{Introduction}

Stepping into a new era since late $20^{\text {th }}$ century, Chinese higher education has witnessed many great changes, among which the upgrading of some local academies is a typical one. In spite of their current capacities in collection, staff and building, some problems still exist in the quality and structure of books, service contents and methods, staff allocation and management and so on. With an analysis on the features and problems in the libraries of some newly-upgraded local undergraduate institutions in accordance with our library's reality, this article is to propose some new ideas with the hope to make a humble effort in helping other libraries to serve teaching, research and local economic construction in a better way.
\end{abstract}

\section{Features of Newly-upgraded Local Undergraduate Institution Libraries}

\subsection{Features in Staff}

Newly-upgraded local undergraduate institution libraries generally suffer from insufficient staff as well as wide-ranging qualities. With the expansion of these undergraduate institutions, a multi-functional, multi-level and overall service seems too much for their libraries. In addition, engaged in such over-loaded work, it is impossible for their staff to spare time for professional training or continuing education, hence resulting in the lack of library staff with reasonable age structure, favorable political quality, high professional and management competence, and therefore, influencing their service quality and management level.

\subsection{Features in Service Objects}

In order to improve their qualities and levels, newly-upgraded local undergraduate institutions make great efforts to introduce some experts and scholars with rich teaching and research experience in addition to encouraging their existing staff to concentrate more on teaching and research, hence calling for a collection of books with width and depth. Besides, better service is also required by higher-level student readers.

\subsection{Features in Document Resources}

Due to their formerly small-sized collections, newly-upgraded local undergraduate institution libraries have an unreasonable collection structure due to the short time and heavy load in book purchasing, and therefore, fail to satisfy their readers, especially those science ones. Therefore, it is safe to say that the current document resources of these libraries are unable to satisfy the requirements for professional and systematic services yet.

\section{Major Problems in Newly-upgraded Local Undergraduate Institution Libraries}

\subsection{Lack and Low Quality of Professional Staff}

Man being the major element in library development, professional people seem more important. With the current insufficient professionals mainly allocated in a few university libraries with long history and high level, these newly-upgraded ones are in bad need of such professionals. Actually, many libraries of this kind are hindered in their development just due to the lack of staff, professional staff and those in computer and network. What's more, a majority 
of library staff are characterized by poor academic background, onefold knowledge structure, low professional competence, poor sense of service and initiative, hence failing to fulfill the requirements of knowledge-based economy and prosperous higher education.

\subsection{Unreasonable Collection Structure and Onefold Document Types}

As required by Undergraduate Teaching Assessment conducted by the Ministry of Education and Undergraduate Teaching Random Assessment Programme for Common Higher Education Institutions (for trial implementation), any upgraded undergraduate institution library is expected to have 80 to 100 books for each student in 5 years after its upgrade. According to our surveys, because a half or even two thirds of their books are newly-purchased and mainly about social science, those readers specialized in science cannot be satisfied. In addition, these libraries also suffer from onefold document types, in which printed books and periodicals take the most proportion, while materials in foreign languages and electronic documents are insufficient in different degrees.

\subsection{Laggard Basic Facilities}

Due to so many problems confronting a newly-upgraded undergraduate institution such as the construction of dormitory buildings, teaching buildings, laboratory buildings, its library has to give way to others although its importance has been realized. With the rapidly increasing number of teaching faculty, students as well as books, its insufficient capacity has led to severely incompetent per capita reading space. What's worse, computer software is also lagging behind. Let's take the library of Nanyang Institute of Technology as an example. Wenjin book management system was originally introduced in 1996 and then in 1999 we developed our own automatic book management system, which is flexible to adjust but unsteady, inconsistent with the international standard and poorly adapted to the resource-sharing environment. Accordingly, it calls for upgrade to fulfill readers' satisfaction in acquiring timely and accurate knowledge and information.

\subsection{Unreasonable Staff Allocation and Disordered Work}

A lot of newly-upgraded libraries have exerted every effort to solve the contradiction between the great number of readers and the poor reading capacity. For example, our library is open all day long and deals with book retuning in intensive periods now. Of course, readers' satisfaction will be fulfilled better in this way. However, it causes the contradiction between a severe waste of staff in some departments (a large part of staff stay idle except for the intensive periods of placing books on shelves) and a severe shortage of staff in others (two shifts are required every day in all departments open to readers and therefore there is a bad lack in information service and cataloguing staff). In addition, incomplete systems have also led to unclear responsibilities at different posts.

\section{Management Countermeasures for Newly-upgraded Local Undergraduate Institution Libraries}

\subsection{Establishing Efficient Library Staff}

Talented people, technology and resources are three key elements in library management, among which talented people are the decisive one. First, choosing a really competent head seems particularly important for the whole personnel management. A person who is devoted to library work and has experience in library management and practice is an ideal choice. Second, people with professional and management competence should be chosen for department deans, which are also important for a library's creative work. Finally, measures should be taken to improve the quality of library staff. Since our upgrade in 2004, our library has adopted the following measures to overcome some former problems: (1) some regular training courses have been held by inviting some experts or sending our staff to attend some courses in order to improve our abilities in theory as well as practice; (2) the existing professionals in library management and computer technology have been made full use of to encourage their enthusiasm and creativity; (3) we have also been organized to study and inspect and exchange with other libraries in order to learn their experiences, broaden our sights and increase our knowledge; (4) shifts among different departments and posts have been conducted regularly in order to inform every member of different operation procedures and help them to grasp various skills; (5) position management has been strengthened and the competition system has been set up to push the staff to devote themselves to their work. By conducting the above measures, we have succeeded in improving our whole staff's comprehensive quality as well as establishing efficient staff gradually.

\subsection{Employing Student Assistants to Relieve Staff Shortage}

It has been long-existing practice in western university libraries to employ a great number of students in their daily routine. Currently, a lot of Chinese university libraries are also using students in their basic and mechanical tasks, such as being on duty, putting books on shelves and tidying shelves, processing and examining new books and other non-professional tasks. Obviously, this is a good way to relieve the current staff shortage in these newly-updated university libraries as well as to provide some part-study and part-work opportunities for poor students.

\subsection{Reasonably Collecting Document Resources with Limited Funds}

Most newly-updated undergraduate institution libraries face the greatest difficulty of a severe shortage of document 
resources as well as quite limited funds. Therefore, they are supposed to try their best to use funds efficiently in key parts. According to our reality and other institutions' practice, we think that the following two measures will give some help: (1) we can buy some popular and practical books at a quite low price from some large presses with our cooperation with professional booksellers; (2) about half of our funds can be used to purchase books by inviting bidding in order to get more discount as well as to allocate document resources according to our specialty arrangement. In addition, collection structure should be adjusted from time to time according to specialties and courses, which requires the purchasing staff to learn well about the arrangement of different specialties, readers' demands and publishing of books, to have an overall design for collection structure in the proportion of different books in purchasing and the number of copies, and then to establish scientific collection structure with special characteristics by following professional, systematic and practical principles. As for our library, first, we lay down Rules for Book Purchasing, in which all details about purchasing of document materials give us rules to follow; second, directors from all departments and some backbone teachers in teaching and research have been chosen to form our book purchasing committee to assist the library to purchase books in various specialties. In this way, library purchasing staff's loads will be lessened and the purchased book materials will better satisfy readers in different specialties

\subsection{Conducting Outsourcing of Business and Technical Tasks}

Due to the above mentioned shortage in library staff, especially professionals in library and computer technology, great difficulty has been caused in fulfilling a lot of technique-intensive tasks. Accordingly, we can cooperate with others in the form of outsourcing. Taking our self-developed automatic software into consideration, the following services can be outsourced in order to achieve better effect and efficiency in our library: (1) requiring book suppliers to attach stamps, magnetic stripes, bar codes and establishing individual registration accounts besides to guaranteeing the quality of books as mentioned in our contracts; (2) back issue binding ; (3) inviting computer professionals from other departments to manage and maintain our computerized management system regularly.

\subsection{Facilitating Network Construction and Modernization}

The automatic, net-based and modernized level of its library is one of the important symbols to show an undergraduate institution's teaching quality. Net is the only solution for a library's automatic development, the material base for its information service, an important way to share resources with others as well as the main goal for all libraries. It should be realized that modernization answers the need of our times and advanced technology and facilities are necessities for modernization and service improvement. Therefore, the libraries in those newly-upgraded institutions should plunge themselves into the information network of the whole society to achieve their modernized management as soon as possible.

To be more specific, first of all, these libraries should set up their LANs to realize the automatic and net-based management of their acquisition, cataloguing, collecting, exchanging, and public searching procedures. Second, their LANs can be connected with any other net through campus network to realize the sharing of information and resources. Although our library established our LAN in 1996 and it has become one part of our campus net, our automatic management software is still lagging behind nowadays. Therefore, we are applying for special funds from our university to purchase new automatic book management software in order to serve teaching, research and local economic construction.

\subsection{Expanding Service Range and Improving Service Quality}

Most newly-upgraded undergraduate institution libraries only offer onefold and passive service in book borrowing and returning and offer their consultation service by waiting for readers to come in person or ringing up. With the rapid development of information technology and the constant expansion of institution scale, libraries should make some adjustments in their ways to deliver service in which the current collection and automatic methods should be made full use of to improve their service quality. With the hope to strengthen our service functions, our library takes two new measures. First is our follow-up service: special staff allocated to contact with teachers with projects are supposed to learn about the going-on of projects and demanded materials and then to offer them catalogue information, indexes of specialized materials and the latest research tendencies, hence saving the researchers' time in searching for materials and hence more time in their researches. Second is delivering books to administrative leaders and academic backbone teachers. Third is offering service in book borrowing and returning, answering questions on the net and subject follow-up service to the back bone staff in research and technology in the local well-known enterprises. By conducting these measures, we are definitely able to improve the status of library in an institution or even in the local area. Currently, our library is adding more new contents on our campus net and our library's homepage as a preparation to set up an announcement system of disks enclosed in books and a periodical database.

\subsection{Constructing a Special Collection and Sharing Resources}

Here a special collection means that a library collection has formed certain scale in quantity, kind, variety in some fields or subjects, has high ranks, information values and high document guaranteeing rate. With special collection being the 
core part in collection construction, priorities should be given to this part, in which the goal for the document construction in some key branches and specialties should be set to a quite high rank, with an emphasis on their replacement in variety and quantity and the effort to keep their consistency, integrity and systematicness. Actually, for us newly-upgraded institution libraries, it is particularly important to construct a specialized collection of books. In the case of our university, due to our specialty in science branches, books in architecture, mechanism, electronics and computer take up over $70 \%$ in our library's total collection, which guarantees our specialized document resources. However, due to the difficulty to set up our own document resources system in a short time, sharing document resources seems to be particularly significant, especially those electronic resources kept in some large libraries.

\section{References}

Jia, Guang. (2002). A Research on the Location of the Library of an Upgraded University. Library and Information Service. (5).

Liu, Xiaoqian. (2002). The Ideas on Developing Local University Libraries in the New Period. Journal of Shiyan Technical Institute. (1).

Mo, Zhenxuan. (2004). On the Exploitation of the Library Information Resources after a Technological College Upgraded to a University. Library Construction. (1).

Qiao, Wenming. (2001). Information Resources Construction of University Libraries in Network Environment. Library Tribune. (5).

Wang, Zhen. (2003). Hindering Elements and Countermeasures in Library Development. Researches in Library Science. (1).

Wang, Zhiqiang. (2003). Information Technology and Library Development. Library Tribune. (5). 